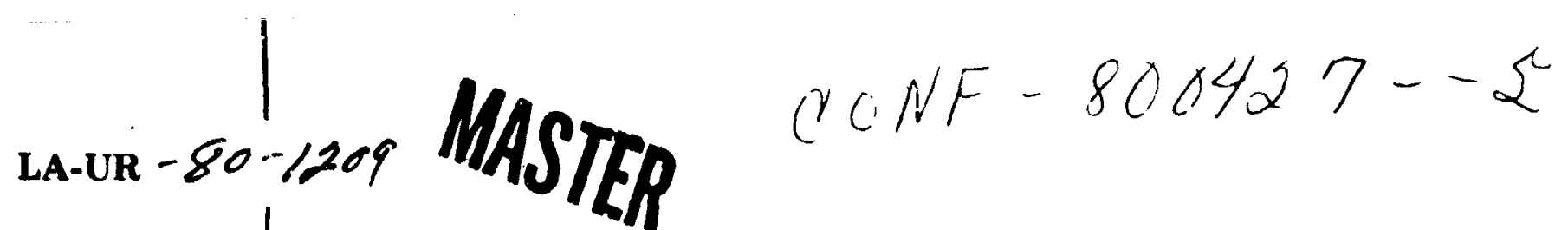

TITLE: A TRITIUM MONITORING SYSTEM USING A MODIFIED KANNE CHAMBER FOR USE IN TRITIUM CONTAMINATING ENVIRONMENTS

AUTHOR(S): D. F. Anderson and R. D. Hiebert

SUBMITTED TO: American Nuclear Society Topical Meeting on Tritium Technoiogy in Fission, Fusion, and Isotopic Applications, Dayton, Ohio, Apri1 29 - May 1, 1980

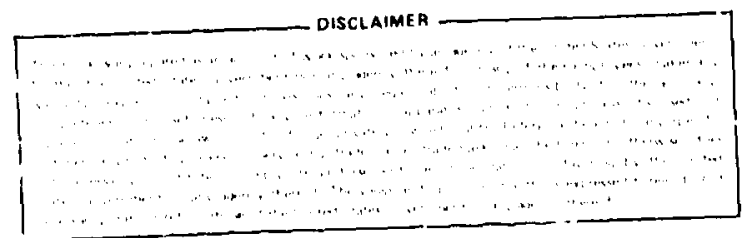

By ecceptance of this article for publication, the publisher recornizes the Governmeti's (license) righte in any copyrigbt and the Governmeni and its authorized representatives have unreatricted r!cht to roproduce in whole or In part onid erticle under any copyright eecured by the publisher.

The Loe Alamos Scientific Lab-ratory moueste that the publisher identify this article an work performed under the suopices of the USERDA. 


\section{A TRITIUM MONITORING SYSTEM USING A MODIFIED KANNE CHAMEER FOR USE IN TRITIUM CONTAMINATING ENVIRONMENTS}

By

D. F. Anderson

R. D. Hiebert

\section{ABSTRACT}

A Kanne chamber has been redesiyned to reduce its sensitivity to such contaminants as tritium water vapor and tritiateri oil. The high voltage electrode has been replaced by a wire cylinder and the collection electrode has been reduced in diameter. The sensitivity to contariination of the chamber hias been reduced by about a factor of 40 . The jesign allows for decontamination of the chamber in place. The improved electronics used is alsc discussed. 


\section{By}

D. F. Anderson

R. D. Hiebert

\section{Introduction}

The Kanne chamber has been used for over two decades to monitor radioactive gases. The advantage of this chamber is the high sensitivity due to its large active volume. A converitional 51.51 iter Kanne chumber, as described by Hoy, [1] is shown in Fig. 1. It consists of three concentric cylinders, with the outer and inner cylinders at or near ground potential while the intermediate cylinder is operated at about $200 \mathrm{~V}$. The region between the outer and intermediate cylinders serves as an ion trap. The inner region (shown shaded) is the measuring chamber, with the inner cylinder acting as the collector electrode.

Under normal operating conditions, usir.g filtered air, contamination is not a major uroblem. However, when exposed to high concentrations of some radioactive gases such as HTO, or to air contaminated wilh tritiated oil, there tends to be a buildup of activity which greatly reduces the sensitivity of the chamber at low tritium concentrations. This residual activity can somet imes be removed by several hours of air purging. Heat is also successfully used for decontamination and so is disassembly and cleaning. Occasiona lly, chambers must be permanently removed from service due to contamination.

The standard technique is to measure the current with an electrometer with a logarithmic scale covering the current range of $10^{-13}$ to $10^{-7} \mathrm{~A}$. A strip chart recorder with a si:i decade range is then used to record the output. In order to determine the amount of tritium that has passed through the chamber, the orea under the logarithmic trace must be integrated by hand. This can be very tine-consuming and introduces inaccuractes, particularly when a sudden excursion (spike) is experienced. Another drawback of this system is that there is no means of zeroing the electrometer :0 subtract a constant background.

Under ideal conditions, concentrations of $5 \times 10^{-6}{ }_{\mathrm{HC}} \mathrm{Cl}_{\mathrm{cm}} \mathrm{cm}^{3}$ can be measured with this systen. This is the occupational concentration guide (CG) 1 imft of tritium water vapor in air in the U.S.A.? 
In order to improve the sensitivity of the Kanne chamber to tritium and to improve the ease of determining the total amount of tritium passing through the system, we have redesigned both the chamber and the electronics.

\section{Chamber Design}

In order to reduce the problem of contamination and improve the ability to decontaminate our chamber, we improved the design of the Kanne chamber shown in Fig. 2. The objective was to reduce the sensitive area, that is, the surface area whose contamination would contribute to the background of the chamber. The high voltage cylinder of the conventional Kanne was replaced by a wire cylinder $78.7 \mathrm{~cm}$ long and $30.5 \mathrm{~cm}$ in diameter, made of forty-five $0.2 \mathrm{~mm}$ diameter nichrome wires running paraliel to the center electrode. The wires are spaced every $10.7 \mathrm{~mm}$. The conventional $76 \mathrm{~mm}$ diameter central collector electrode was replaced with a $6.4 \mathrm{~min}$ diameter aluminum rod with a sensitive length of $77.2 \mathrm{~cm}$. Figure 3 shows a detail drawing of the intake end of this chamber. The wires are stretched between ninety ceramic pieres on two inner support rings. These rings are connected to outer support rings by six short rods. The outer support rings are themselves supported by eight connecting rods fastened to the exhaust end of the chamber. All rings and rods are held at ground potential. A photograph of the high voltage assembly and center electrode is shown in Fig. 4.

The maximum energy of a tritium beta is $18 \mathrm{keV}$ with a mean energy of $5.6 \mathrm{keV}$. Thus, the betas have a maximum range in air of about $1 \mathrm{~mm}$ under standard conditions, with the mean range a little over $1 \mathrm{~mm}$. At Los Alamos, New Mexico, U.S.A., where the atmospheric pressure is only ahout $75 \%$ of that at sea level, the maximuin range is about $10 \mathrm{~mm}$. For this reason, all surfaces outside of the high voltage cylinder (t.e., connecting rods and chamber wall) are greater than $1 \mathrm{~cm}$ from the wires. Since the support rings are grounded, the majority, if not all, of the conization due to their concamination will terminate in the ring. Thus, this contamination will not contribute to the signal. The supportid end of the collector electrode is shielded to prevent detection of co.itamination from the support rings or the chamber end. The sensitive area of the improved kunne is less than $266 \mathrm{~cm}^{2}$ while the sensitive area of a conventional kanne chamter is about $1.1 \times 10^{4} \mathrm{~cm}^{2}$. This is a reduction in sensitive area by a factor of 40 . 
This new design greatly improves the ability of the chamber to be contaminated, if need be. The high voltage wires can be decontaminated $i$ place by passing a hearing current through them. The center electrode is nounted by four external screws and can be easily removed. This electrode can te either replaced or decontaminated. Decontamination can be accomplished in a few minutes without removal of the chamber from service.

Since this design eliminates the internal ion trap, an external deionizer is provided. It consists of $0.8 \mathrm{~mm}$ thick stainless steel plates (20) spaced at $3.2 \mathrm{~mm}$ centers. Alternate plates are connected to the same high voltage supply as the Kanne chamber, with the remaining flates at ground potential. An external HEPA filter is used to remove dust and oil mist.

\section{Electrometer Design}

A new electrometer, called the Model 39 Electrometer-Chargemeter, is shown in Fig. 5. It has been designed to measure currents as low as 1 fA $\left(10^{-15} \mathrm{~A}\right)$, and to integrate these currents for a measure of accumulated charge. The instrument is intendea to be used with ionization trinsducers having grounded collecting electrocie configurations. This instrument is not only useful with Kanne chambers but with ion chambers having much smaller detaction volumes.

The electrometer has 4 decades of range, with a switch to select the current range of interest. Logarithillic and linear display of current is furnished in analog format. In the rost sensitive configuration, the range is $1 \mathrm{PA}\left(10^{-12} \mathrm{~A}\right)$ full scale, with $0.1 \mathrm{fA}\left(10^{-16} \mathrm{~A}\right)$ detectability. The chargemeter readout is a digital display that covers 10 decades from $10^{-1 \hat{c}} \mathrm{C} /$ digit to $10^{-2} \mathrm{C}$ full scale. Readout is with 3 decades of digital indicators and exponent multipliers. Rarige of charye readout selection is elther manual with a seiector switch or auto-ranging, whereby the 3 most significant digits with non-zero information are displayr.d along with the exponential multiplier. Both analog anú digital data are presented to output connectors for use in data acquisition systems.

The electrometer operational amplifier and its associated high-megohm resistors are housed in a separate temperature-controlled oven, sliown on the left in Fig. 5. Input is through a coaxtal connector. This configuration allows the shortest distance from the collector of the tritium a hamber 
to the amplifier. There is insignificant variation in gain or instrument zero with changes in ambient temperature. The power and control 1 ines for this assembly are carried in a multiconductor cable, with the output signal on a separate coaxial connector. The circuit desiy. allows a steady-state background of an instrument to be suppressed. Thus, the constant background due to contamination will not contribute to the integrated sharge measured by the instrument.

\section{Performance:}

To calibrate this improved monitoring system, it was placed in series with a conventional 51.6 liter Kanne chamber at an operating facility. The air passes through the improved chamber before entering the latter chamber. The calibration for the improved chamber was found to be $1.8 \times 10^{7} \mu \mathrm{Ci} / \mathrm{cm}^{3}$ per amp compared to $2 \times 10^{7} \mu \mathrm{Ci} / \mathrm{cm}^{3}$ per amp for the conventional chamber. This implies an effective volume of about 57 liters for the improved chamber.

The air which the two chamber's sampled was very contaminating. Before the new chamber was introduced, the background of the conventional chamber had increased from about $1.4 \times 10^{-12} \mathrm{~A}$ to $2.8 \times 10^{-12} \mathrm{~A}$ but with less increase thereafter. This is probably due to the better filtering of the first chamber. Upon installation of the new tritium monitor, the electrometer was zeroed. After 16 weeks of constant use, the zero still dis not require adjustment. With this system, steady-state concentrations of ajout $1 \times 10^{-7} \mu \mathrm{Ci} / \mathrm{cm}^{3}$ (about $5 \times 10^{-15} \mathrm{~A}$ ) should be measurable, even under the contaminating environment of the test sicuation. It was found that when measuring concentrations on the order of $10^{-3} \mu \mathrm{Cl} / \mathrm{cm}^{3}$, the new cilamber read slightly lower ( $2 \%$ ) than the conventional Kanne. This is undoubtedly due to the smaller collecting electrode which allows more recombination at high concentrations.

\section{Concluston}

The improved Xanne tritfum monitoring system described above should greatly improve the monitoring capability of low concentrations of tritium, particularly in contaminating environments. With the improved electronics the volume of the monitor can be greatly reduced, while maintaining high sensitivity. Concentrations of $10^{-6}{ }_{11} \mathrm{Cl} / \mathrm{cm}^{3}$ may be measured with a $1-1$ ter chamber in a short perlod of time. The reduction of sensitive suriace area 
is also adaptable to smaller chambers. These smaller instruments will have much faster response time and much less bulk, making them more convenient than Kanne systems. Smaller instruments can also be designed which, besides being less susceptable to contamination, will also be linear over a very large dynamic range. The improved electronics and the reduction of sensitive area opens the avenue to much improved conventional tritium monitoring. 


\section{References}

1. Hoy, J. E., Health Physics 6 (1961) 203

2. U.S.D.0.E. Manual Chapter \#0524, Standards for Radiation Protection, Apri1, 1977

\section{Figure Captions}

Figure 1 - Conventional 51.5 liter Kanne Chamber

Figure 2 - Improved Kanne Chariber

Figure 3 - Detail of the Improved Kanne Chamber

Figure 4 - Photograph of High Voltage Assembly and Center Electrode

Figure 5 - Model 39 Electrometer-Chargemeter. The temperature-controlled oven containing the amplifier is on the left. 


\section{KANNE GHAMPER}

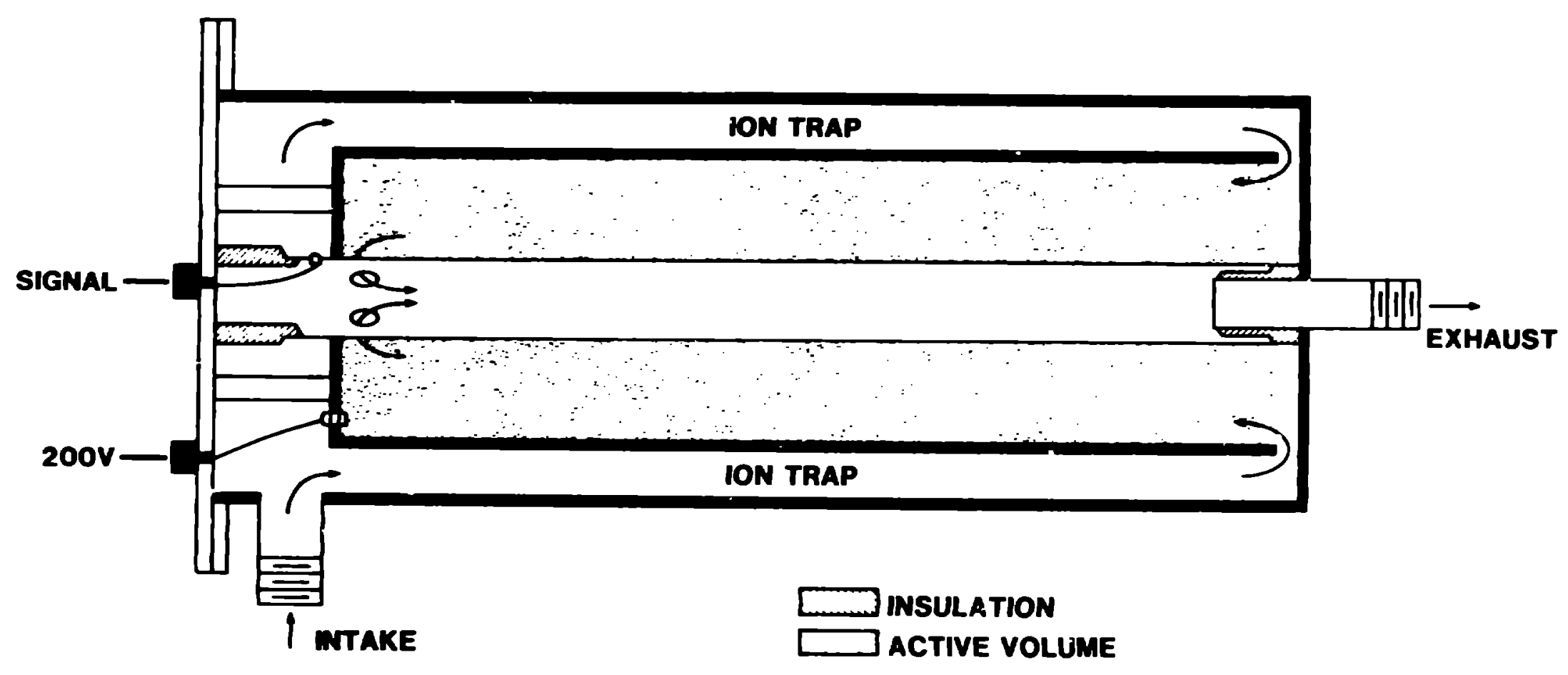


IMPROVED KANNE CHAMBER

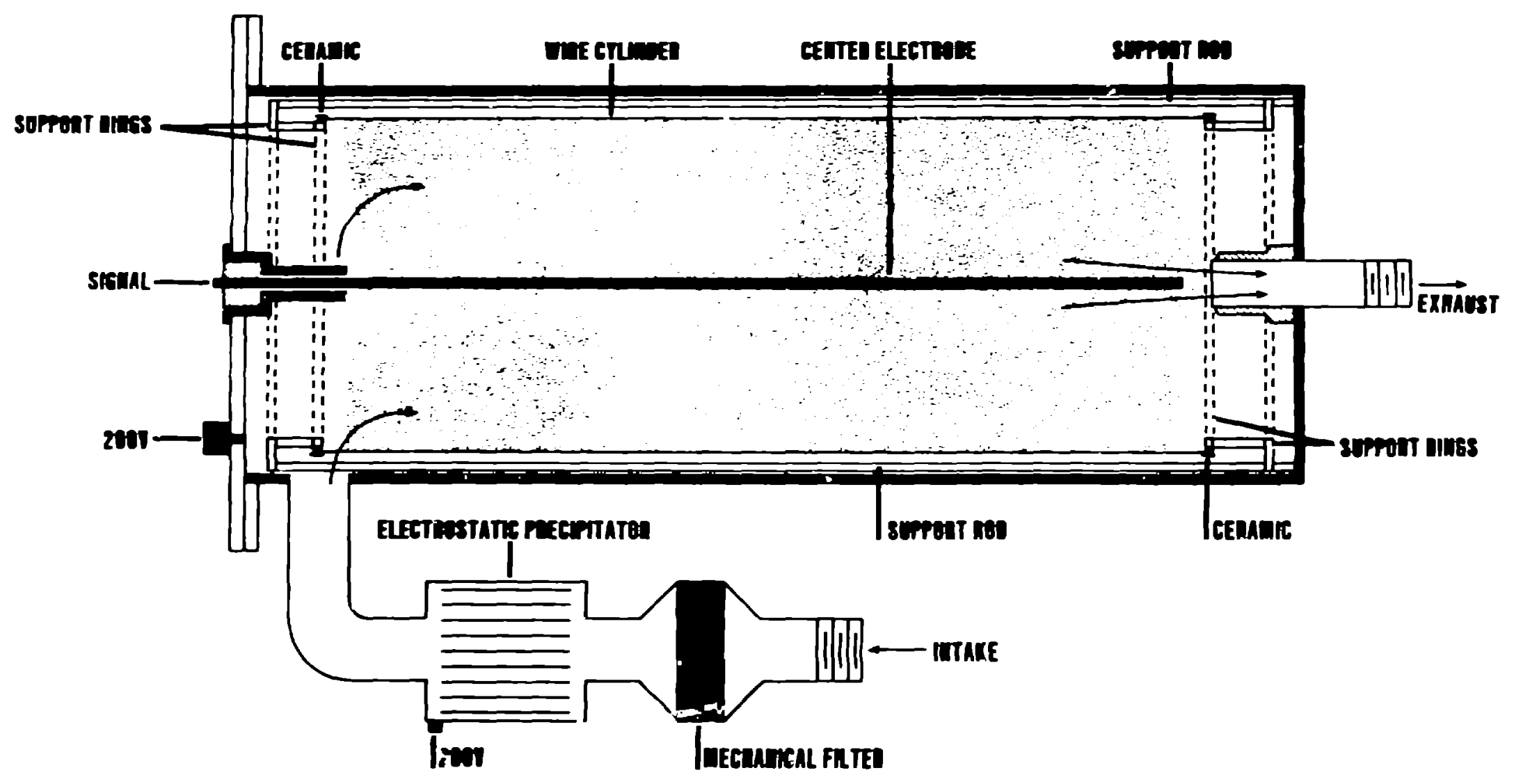

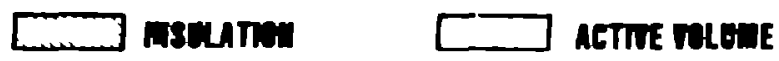

FIGURE ? 


\section{DETAIL OF IMPROVED KANNE CHAMRER}

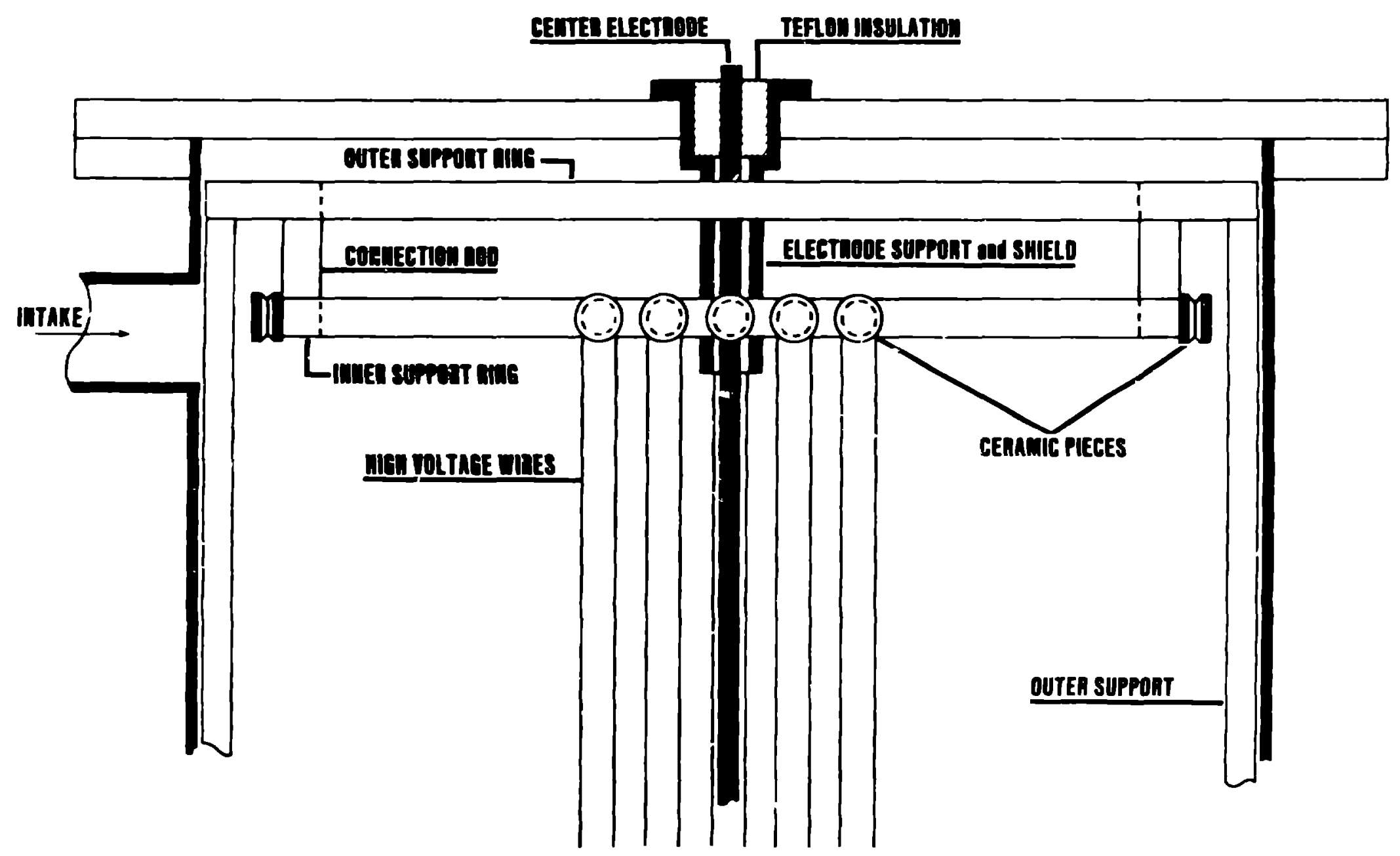

FIGURE 3 


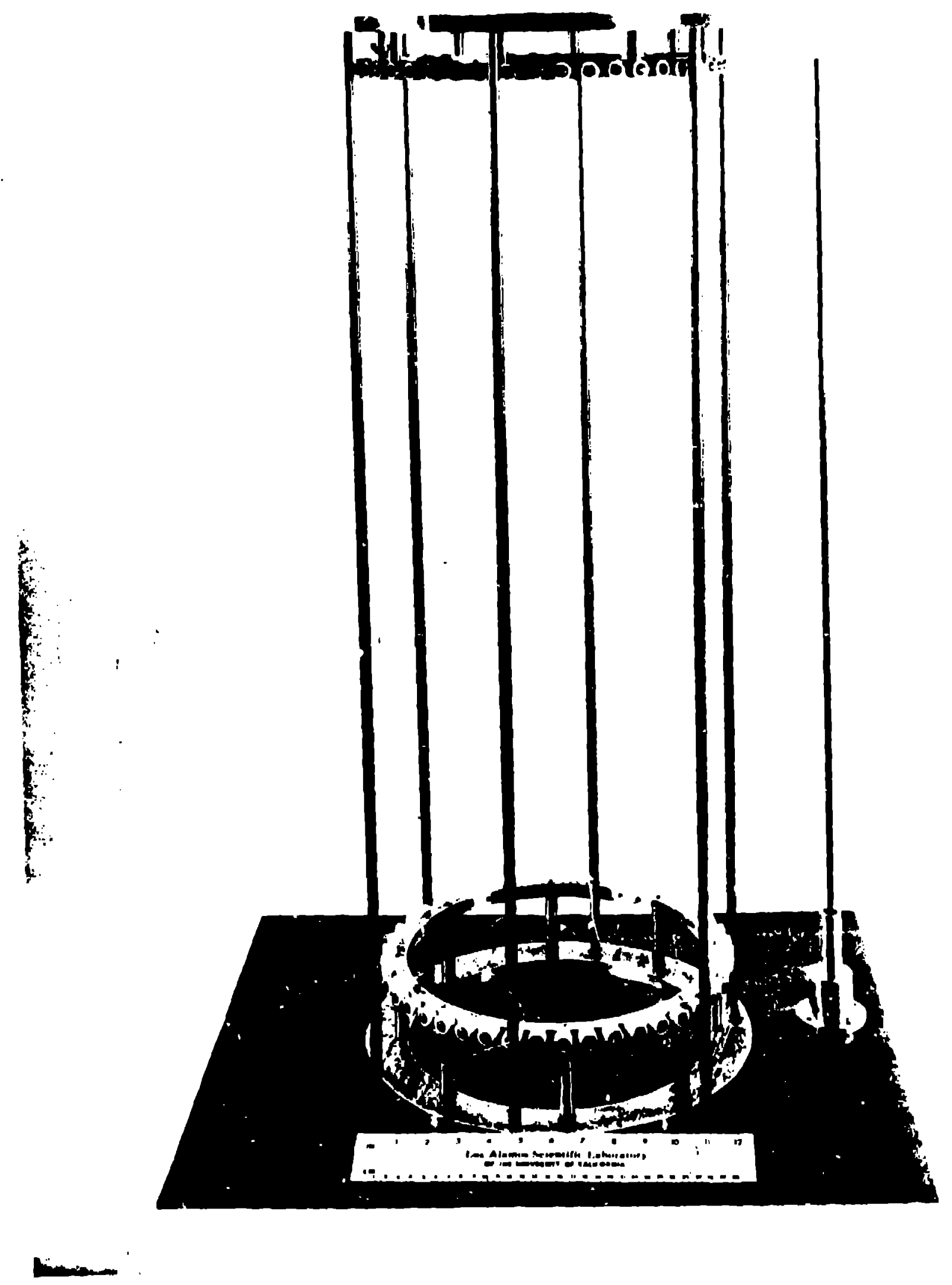

FIGURE 4 


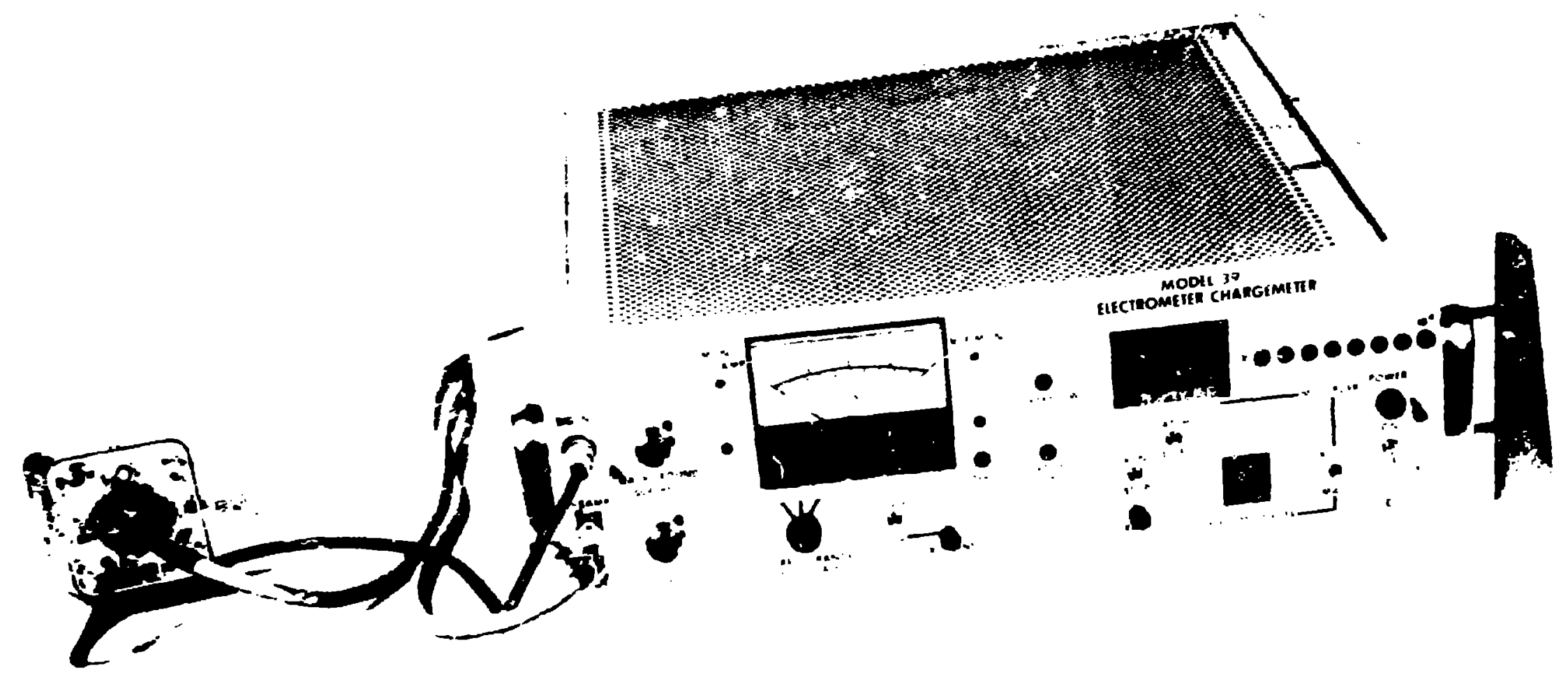

. - - D.

$+\infty$

6
FIGIFE 5 